\title{
Alteration of Human Chorionic Gonadotropin Levels among Pregnant Women with Morning Sickness Attending Antenatal Care Services at Ishaka Adventist Hospital, Uganda
}

\author{
Atusiimirwe Jovile Kasande, Ejike Daniel Eze1* ${ }^{*}$, Iliya Ezekiel², Karimah Mohammed Rabiu ${ }^{3}$ \\ ${ }^{1}$ Department of Physiology, Faculty of Biomedical Sciences, Kampala International University, Kampala, Uganda \\ ${ }^{2}$ Department of Biological Sciences, Faculty of Pure and Applied Sciences, Federal University, Wukari, Nigeria \\ ${ }^{3}$ Department of Biological Sciences, Faculty of Science, Yobe State University, Damaturu, Nigeria \\ Email: *daniel.ejike@kiu.ac.ug
}

How to cite this paper: Kasande, A.J., Eze, E.D., Ezekiel, I. and Rabiu, K.M. (2017) Alteration of Human Chorionic Gonadotropin Levels among Pregnant Women with Morning Sickness Attending Antenatal Care Services at Ishaka Adventist Hospital, Uganda. Journal of Biosciences and Medicines, 5, 55-77.

https://doi.org/10.4236/jbm.2017.58005

Received: June 6, 2017

Accepted: August 12, 2017

Published: August 15, 2017

Copyright $\odot 2017$ by authors and Scientific Research Publishing Inc. This work is licensed under the Creative Commons Attribution International License (CC BY 4.0).

http://creativecommons.org/licenses/by/4.0/

\begin{abstract}
Globally, $50 \%$ - $90 \%$ of pregnant women are affected by morning sickness of pregnancy, especially during the first trimester. Therefore this study was carried out to establish if there is association between urinary hCG levels and severity of nausea, retching and vomiting among pregnant women attending antenatal care (ANC) services at Ishaka Adventist Hospital (IAH). It was a quantitative cross-sectional study in which a pre-tested and standardized questionnaire with a mixture of both open and closed ended questions was used to collect data from respondents to determine the clinical history, socio-demographic characteristics, and clinical features of morning sickness and/or hyperemesis gravidarum. Urine samples were also collected from each participant and analyzed using the Beckman Coulter Access 2 immunoassay system and Access Total hCG reagent pack at Mbarara University of Science and Technology. The findings showed that $63 \%$ of the respondents experienced morning sickness with the majority having a mild form. There was also no significant relationship between hCG levels and severity of morning sickness and no correlation between physiological characteristics (gravidity, age and weight) (correlation coefficient $-0.05186,-0.0469$ and 0.157 respectively). In addition, there was no correlation between cravings, aversions and morning sickness (correlation coefficient -0.0262 and 0.227 respectively). In conclusion, the study revealed that there was a high prevalence of morning sickness of pregnancy although, it was mild; no association between severity of morning sickness and levels of hCG as well as correlation between cravings and aversions with hCG levels in the study population. Considering the limi-
\end{abstract}


tations of this study, it is recommended that studies should be undertaken for the quantitative determination of total hCG levels in urine for all pregnant women with morning sickness to be able to draw a definitive conclusion.

\section{Keywords}

Morning Sickness, hCG, Pregnancy, Antenatal Care

\section{Introduction}

There are many theories about what causes morning sickness most of which are not proven, although the most widely-held view is that it is probably a combination of factors that may include, among other theories, unstable blood sugars, hormone activity, changes in blood composition and the sex of the baby. The term morning sickness is used to describe symptoms of nausea, retching and vomiting during pregnancy, a term that appears to be a complete misnomer because symptoms occur throughout the waking hours not just in the morning and the fact that the majority of women who experience these symptoms bear healthy babies, an indication that the pathological state implied by the word "sickness" is misleading [1]. Age has reported to be one of the factors affecting morning sickness. The younger the pregnant women are the more the tendency to exhibit severe symptoms of morning sickness [2] [3] [4]. Reports also indicate that increased symptoms of morning sickness as well as hyperemesis gravidarum are more common in young age up to 26 years; and that the women of older age are less likely to have symptoms of morning sickness or hyperemesis gravidarum [5]. However, some authors also report that women's age is not related to symptoms of morning sickness, especially to hyperemesis gravidarum [6] [7] [8] [9]. hCG is produced in the earliest stages of pregnancy. During early pregnancy it plays a role in survival of the corpus luteum [10] and in stimulating the thyroid gland [11], and it also appears to have a significant role in the implantation of the blastocyst and protection of the embryo against immune attack at the fetal-maternal boundary. The hormone is initially produced by the embryo and, therefore, also acts as a marker for its presence [12]. According to Goodwin et al. [13], it is not the total concentration of hCG that correlates with nausea, retching and vomiting. Therefore, the levels of its entity hCG correlate with both occurrence and intensity of these ailments. The symptoms develop with increasing hCG concentrations and most intensive ailments are connected with the time of the highest levels of hCG in 10 - 12 weeks of gestation [13]. In early pregnancy, hCG secretion pattern tends to parallel the timing of pregnancy related symptoms and has been a potential mechanism triggering nausea and vomiting [14]. It has been reported that there is a positive association between levels of hCG with nausea, retching and vomiting [14]. However Jordan et al. [15] and Alyatama et al. [16] did not find any positive association between levels of hCG and morning sickness. The hormone hCG is regarded as the main underlying cause 
of morning sickness, although there is contradicting information regarding the effectiveness of hormonal levels and severity of morning sickness [14] [17] and this inconsistency may reflect lack of direct causal association and/or variation across sample characteristics. Whereas large numbers of women $(50 \%-90 \%)$ are affected with morning sickness globally, the levels of hCG responsible for the severity of nausea, retching and vomiting are not known for certain, leave alone the fact that there might be variations in different populations. The essence of study was informed on the facts that there exists limited information on the factors that may be influencing the severity of hyperemesis gravidarum/morning sickness at various levels of hCG, other than the hormone alone, hence requires investigation. Whereas large numbers of women (50\% - 90\%) are affected by morning sickness, globally, the levels of hCG responsible for the severity of nausea, retching and vomiting are not known. In Uganda, there are no reports on any study done to relate the severity of morning sickness and hCG levels in the urine of the affected women. Therefore, results from this study are going to contribute knowledge to what is known about the condition and help design appropriate interventions in cases of severe morning sickness of pregnancy. Results from the study are also useful for women who suffer from this condition, since dissemination of the findings will contribute to pregnant women's ability to respond to various grades of morning sickness of pregnancy. Therefore, the present study was carried out to evaluate the alteration of human chorionic gonadotropin levels among pregnant women with morning sickness attending antenatal care services services at Ishaka Aventist hospital, Uganda.

\section{Materials and Methodology}

\subsection{Study Design}

It was a quantitative cross- sectional study that was carried out to determine the prevalence, risk factors and the relationship between the levels of urinary hCG and severity of morning sickness among women attending ANC at Ishaka Adventist Hospital. It involved use of a pretested questionnaire and laboratory sample analysis which was done using Beckman Coulter Access 2 immunoassay system with the reagent pack called Access total beta hCG ( $5^{\text {th }}$ IS). The principle that was used in this equipment is "the access total beta hCG $\left(5^{\text {th }}\right.$ IS) which is a paramagnetic particle, chemiluminescent immunoassay for the quantitative determination of total hCG levels in urine".

\subsection{Study Setting}

The study was carried out at Ishaka Adventist Hospital which is situated in Ishaka-Bushenyi Municipality, Bushenyi District, South Western Uganda. It is located along the main high way to Kasese, is $350 \mathrm{~km}$ away from the capital city of Uganda called Kampala. Currently, Ishaka Adventist Hospital has 120 bed capacities that serve mostly the poor communities of Ishaka-Bushenyi District. The hospital serves an average population of 50 - 75 mothers in the first trimes- 
ter in a given month. The hospital also offers diagnostic services like, X-ray, ultrasound, general laboratory services including hematology, biochemistries and bacteriology. Ishaka Adventist Hospital also has an ECG. The hospital also has nursing and laboratory schools.

\subsection{Population}

\subsubsection{Target Population}

This comprised pregnant women presenting with nausea, retching or vomiting, who were in the first trimester. The women in the first trimester were considered because this is a period when urinary hCG levels have reached the maximum. However 23 pregnant women without nausea, retching and vomiting were also interviewed.

\subsubsection{Accessible Population}

Pregnant women who are attending ANC services at Ishaka Adventist Hospital and have consented to participate in the study.

\subsubsection{Study Population}

Pregnant women who were in the first trimester and who were receiving ANC services from Ishaka Adventist Hospital during the period of study.

\subsubsection{Calculation of Sample Size}

$$
n=\frac{X^{2} * N * P(1-P)}{M E^{2} *(N-1)+\left(X^{2} * P *(1-P)\right)}
$$

$n=$ Desired sample size; $X^{2}=$ Chi square for the specified confidence level at 1 degree of freedom; $N=$ Population size; $P=$ Population proportion (0.50); $M E=$ Desired margin of error (in proportion) [18]. The calculation for sample size gave the figure of 54 determined as follows:

$$
\begin{gathered}
X^{2}=\frac{\sum(f o-f e)}{f e} \\
\frac{X^{2} \sum(63-75)}{75}=1.92
\end{gathered}
$$

where by fo is observed frequency; $f e$ is expected frequency

From above formula,

$$
\begin{aligned}
n & =\frac{1.92 \times 75 \times 0.50 \times(1-0.5)}{0.05 \times 2 \times(75-1)+1.92 \times 0.50 \times(1-0.5)} \\
& =\frac{36}{0.185+0.48} \\
& =\frac{36}{0.665} \\
& =54 \text { participants. }
\end{aligned}
$$

\subsubsection{Selection Criteria}

1) Inclusion criteria 
Pregnant women in the first trimester who consented to the study.

\section{2) Exclusion criteria}

These included pregnant women in the first trimester that consented but did not answer the questionnaire and those who presented with gastrointestinal disorders, infections and metabolic disorders such as thyrotoxicosis. Pregnant women on antibiotics, iron supplements, chlorpromazine, phenothiazines, methadone and some infertility drugs for example menopur, bravelle, follistim, gonal-F and repronex were also excluded, together with all pregnant women with severe dizziness and headaches. This was to avoid the symptoms interfering with the results of the study.

\subsection{Study Variables}

The study variables included morning sickness (severity of nausea, retching and vomiting) as dependent variables; beta hCG levels as an independent variable and food aversions, cravings, distention of GIT, cross over with TSH causing gestational thyrotoxicosis; alcohol consumption, diet/ nutrition and age among others were studied as intervening variables.

\subsection{Sampling Procedure}

Pregnant women in the first trimester who received ANC services from Ishaka Adventist Hospital were identified with the help of mother-child health passport and ANC In-charge. Ballot papers marked with a "Yes" or "No" were used. Each participant picked a ballot paper without replacement. The researcher took participants through a consent form in order for participants to consent. The researcher interviewed participants having ballot papers written on "Yes" until a sample size of 63 was achieved. This was achieved on different ANC visits. At Ishaka Adventist Hospital on average a population size of 75 first trimester pregnant women is seen monthly. The data was collected within one month. Using confidence interval of $95 \%$ and margin of error of $5 \%$ hence the basis for using a sample size of 63 (Table 1).

However the sample size of 63 participants was used instead of 54 because there were interesting cases which were also interviewed to get the sample size of 63 .

\subsection{Data Collection Methods}

\subsubsection{Study Instruments}

A pre-tested and standardized questionnaire (appendices II and III) with a mixture of both open and closed ended questions was used. Both English and Runyankole versions of the questionnaire were used to allow participants respond on what they understood.

\subsubsection{Measurement Variables}

1) A detailed clinical history included social demographic characteristics, clinical features of morning sickness and or hyperemesis gravidarum, related factors in woman's personal history, and other significant information related to 
Table 1. Required sample size.

\begin{tabular}{ccccc}
\hline \multirow{2}{*}{ Population size } & \multicolumn{4}{c}{ 95\%Confidence interval Margin of error } \\
\cline { 2 - 5 } & $5.0 \%$ & $3.5 \%$ & $2.5 \%$ & $1.0 \%$ \\
\hline 10 & 10 & 10 & 10 & 10 \\
20 & 19 & 20 & 20 & 20 \\
30 & 28 & 29 & 29 & 30 \\
50 & 44 & 47 & 48 & 50 \\
75 & 63 & 69 & 72 & 74 \\
100 & 80 & 89 & 94 & 99 \\
150 & 108 & 126 & 137 & 148 \\
200 & 132 & 160 & 177 & 196 \\
250 & 152 & 190 & 215 & 244 \\
300 & 169 & 217 & 251 & 291 \\
\hline
\end{tabular}

morning sickness and hyperemesis gravidarum were obtained from the participants.

Participants were grouped as shown here under:

Group 1 Women with Nausea only

Group 2 Women with nausea and vomiting only

Group 3 Women with nausea, retching and vomiting

Group 4 Women with none of the above symptoms

\section{2) Methodology to determine prevalence}

The pregnancy unique quantification of emesis (PUQE) index (Laccasse et al., 2008) was used to determine nausea score as follows;

Mild: $<6$

Moderate: 7 - 12

Severe: $\geq 13$

The prevalence $=\frac{\text { Number of participants with the outcome of interest }}{\text { Total number of sampled cases } / \text { participants. }}$

\section{Laboratory investigations}

\section{Measurement of hCG levels}

At the time of interview, urine samples were collected using sterile containers from each participant during morning hours between 08:00 am - 1:00 pm. A small portion of urine was voided in sterile containers. Immediately after collection, urine samples were placed in cooler boxes with ice packs (at $+4^{\circ} \mathrm{C}$ ) to preserve the urinary hCG. The preserved samples were transported to Mbarara University of Science and Technology-Clinical Research Laboratory freezer $\left(-80^{\circ} \mathrm{C}\right)$ in Mbarara, within six hours of collection, to maintain chemical composition of the analyte to be assayed. The equipment Beckman Coulter Access 2 immunoassay system as well as Access Total hCG ( $5^{\text {th }}$ IS) reagent pack were used in sample analysis. The reagent pack was always on board and the process of pi- 
petting both reagent and sample was done by the equipment. Samples were processed as follows:

Samples were defrosted by removing them from the deep freezer. A $200 \mu \mathrm{l}$ portion of the urine samples were pipetted into the sample cups that were put on 10 space samples' rack. The samples' racks were loaded onto the equipment. A work list was then created on the equipment monitor indicating the test required as well as the position of the samples on the sample rack. The analysis of the samples was started by clicking on the run button on the equipment. The sample and reagent pipetted were incubated, and at the end of 30 minutes, an automatic printout of the results appeared on the screen. Then the results were entered on each questionnaire for analysis later on.

\section{3) Methodology to achieve correlation}

The values for two variables were selected from the raw data previously entered into excel spreadsheet. The values were sorted and then copied into Past 3 Software, thereby analyzing the variables by use of one way ANOVA (for several samples) and Tukey's pairwise. The variables that were analyzed here included beta hCG levels and the scores for morning sickness.

\subsection{Data Processing, Analysis and Presentation}

\subsubsection{Data Processing}

The collected data were subjected to processing for easy interpretation and understanding. Collected data were checked for completeness on the same day of collection; and then categorized, coded and entered into excel where it was summarized into tables, charts and graphs.

\subsubsection{Data Analysis}

The data were analyzed using Microsoft office excel and Past 3 Software to examine for correlation between beta hCG levels and severity of morning sickness. The statistical tools that were employed to find if there was significance between two given valuables as well as finding $\mathrm{p}$ values are one way ANOVA (several samples) and Tukey's pairwise.

\subsubsection{Data Presentation}

In addition to texts, tables and figures were used to represent the data. Headings and subheadings that capture the meaning of the raw data were also used.

\subsection{Quality Control}

Pretesting of the questionnaire was carried out at the ANC clinic of Ishaka Adventist Hospital four days prior to data collection and modifications done before commencement of the data collection. The research assistants were trained on how to collect samples from the participants. The Gynaecologist closely observed the process of taking history and examining participants. After collection, the samples were examined by a competent laboratory technician at Ishaka Adventist Hospital laboratory. 


\subsection{Ethical Consideration}

\subsubsection{Informed Consent}

A written consent form (Appendix 1) was given to participants and all the components of the consent form were explained to them. Signing the consent form signified participants' agreement to participate in the study.

\subsubsection{Confidentiality of Data}

All the information collected in this study was given code numbers and only participants' initials were used. The results and the identity of the participants were kept confidential.

\subsubsection{Translation of Protocols}

The protocol involved in the research was translated to the language of the participants who do not speak English, to ensure that the participants fully understood what the research entailed before any procedure was done on them. Also, the participants were asked if there was any religious or other cultural belief that could hinder participation in this research and these were discussed fully with the members of staff before participation commenced.

\subsubsection{Possible Benefits to Participants}

Related obstetric and clinical histories were taken from each participant. There were no other direct benefits to participants but the study suggested integration of measurement of hCG levels among women with morning sickness symptoms, into health services at this facility.

\subsubsection{Possible Risks}

The study involved minimal possibilities of risk, stress and discomfort. In so doing, we observed and asked a few questions. Urine samples were collected from each participant but this was non painful since there was no pricking involved which would leave behind a wound that would take long to heal.

\subsubsection{Privacy to Participants}

All the participants had a right to privacy and this was honored. Urine samples were collected from participants from the washrooms.

\subsubsection{Right to Decline/Withdraw from the Study}

Participants were told that they had a right to withdraw from the study and that this did not in any way affect the kind of care they would be receiving from Ishaka Adventist Hospital.

\subsubsection{Introductory Letter and Ethical Approval}

An introductory letter from Kampala International University-Western Campus Directorate of Postgraduate Studies and Research was obtained and presented to the hospital administration. Ethical approval to conduct the study was also obtained from the Institutional Research Ethics committee. 


\subsubsection{Administrative Clearance}

An administrative clearance from Ishaka Adventist Hospital was also obtained.

\subsubsection{Limitations of the Study}

1) Other common morning sickness symptoms like dizziness and headache interfered with observations. Those with such symptoms were excluded from the study.

2) Taking of women's history was based on their memory which is imperfect. Certain statements and some scenarios were given to help them recall.

3) The early morning samples which contained high concentrations of hCG could have been missed out since some participants would reach hospital later after passing urine. Prior meeting with participants was commenced to give ground rules.

\section{Result Findings}

\subsection{Characteristics of Respondents}

\subsubsection{Age of Respondents}

From Figure 1, those with age ranging from $15-25$ years formed the majority respondents (55\%) while those in the range of 26 - 35 years accounted for $40 \%$, with least percentage (5\%) being in the range of 36 - 45 years; an indication that the proportion of pregnant women declined with age.

\subsubsection{Weight of Respondents}

As indicated in Figure 2, the majority of the respondents (43\%) had weight falling in the range of $51-60 \mathrm{~kg}$, followed by $32 \%$ of the total respondent in the range of $61-70 \mathrm{~kg}$. The rest of the respondents included $11 \%$ falling in the range of $40-50 \mathrm{~kg}, 6 \%$ in the range of $71-80 \mathrm{~kg}$ and $8 \%$ in the range of $81 \mathrm{~kg}$ andabove.

\subsubsection{Gravidity of Respondents}

From the Figure 3 above, $65 \%$ of the respondents, who were the majority, were multigravidae while $35 \%$ of the respondents were pregnant for the first time.

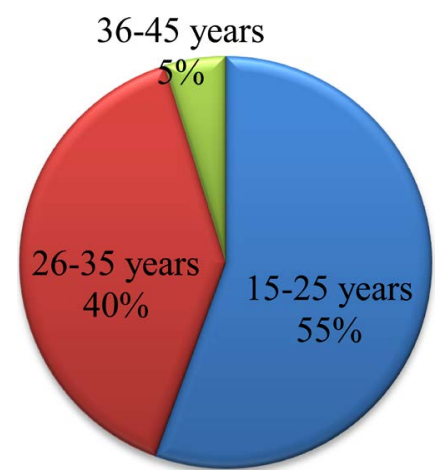

Figure 1. Age distribution of respondents. 


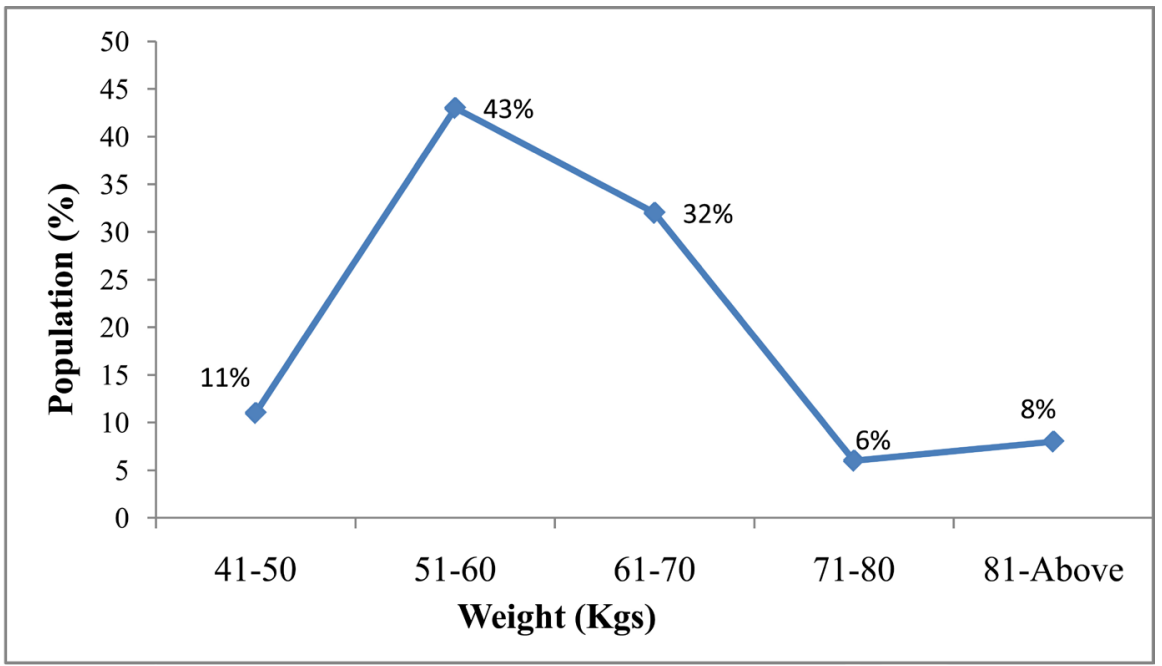

Figure 2. Body Weight distribution of respondents.

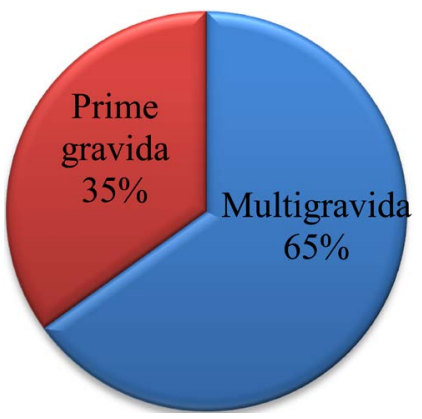

Figure 3. Gravidity of respondents.

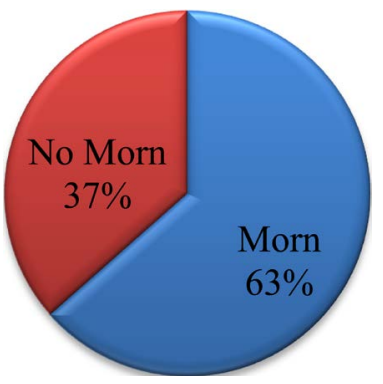

Figure 4. Prevalence of morning sickness among first trimester pregnant women.

\subsection{Prevalence of Morning Sickness among Women Attending ANC at IAH}

\subsubsection{Prevalence of Morning Sickness}

From the Figure 4, 63\% of the total respondents experienced morning sickness (morn), while $37 \%$ of the respondents had no morning sickness (No morn). Using pregnancy unique quantification of emesis (PUQE) index, we scored respondents using nausea, retching and vomiting. From the scores, severity of morning sickness was grouped as Mild; $\leq 6$, Moderate; 7 - 12 and Severe; $\geq 13$. In summary, 23 participants had no morning sickness, 19 had mild, 13 had moderate while 08 had severe morning sickness. 


\subsubsection{Severity of Morning Sickness}

Of the respondents who experienced morning sickness in different forms, 30\% experienced a mild, $22 \%$ the moderate and $11 \%$ a severe form of morning sickness. From these results, majority experienced mild form of morning sickness followed by those who experienced a moderate form.

\subsection{Urinary hCG Levels among Women Attending ANC at IAH}

\subsubsection{Respondents' hCG Levels Distribution}

From Figure 5, the respondents with the least hCG Levels $(<500 \mathrm{mIU} / \mathrm{ml})$ were $3 \%$. In their ascending order of hCG levels were in the following ranges: $11 \%$ in the $901-1100 \mathrm{mIU} / \mathrm{ml}, 13 \%$ in the $1101-1350 \mathrm{mIU} / \mathrm{ml}$ and $16 \%$ in the $500-$ $700 \mathrm{mIU} / \mathrm{ml}$ range, with $27 \%$ having $>1350$ and $30 \%$ falling in the range of 701 $900 \mathrm{mIU} / \mathrm{ml}$. Most of the respondents were in the range of $701-900 \mathrm{~m} \mathrm{IU} / \mathrm{ml}$ followed by those with $>1350 \mathrm{mIU} / \mathrm{ml}$. From these results, a bimodal pattern is seen in the Figure 6 where by two normal distributions with the same variance but different means (hCG ranges) are observed. The two peaks of data indicate that there are two different groups-a large population of pregnant women having lower hCG levels and another large population of pregnant women with higher hCG levels.

\subsubsection{Respondents' hCG Levels and Morning Sickness}

Figure 6 shows a comparison between urinary hCG levels in respondents with no morning sickness (NMS) and those with morning sickness (MS). In the range of $701-900 \mathrm{mIU} / \mathrm{ml}$, six respondents had no morning sickness but 13 respondents had morning sickness. In the highest levels of hCG (>1350 mIU/ml) 3 respondents had no morning sickness while 14 respondents experienced morning sickness. From Figure 7 above, there is a bimodal pattern for morning sickness if the distribution curves are combined. This means that there is a high population of pregnant women with morning sickness having lower hCG levels and another high population of pregnant women with morning sickness but

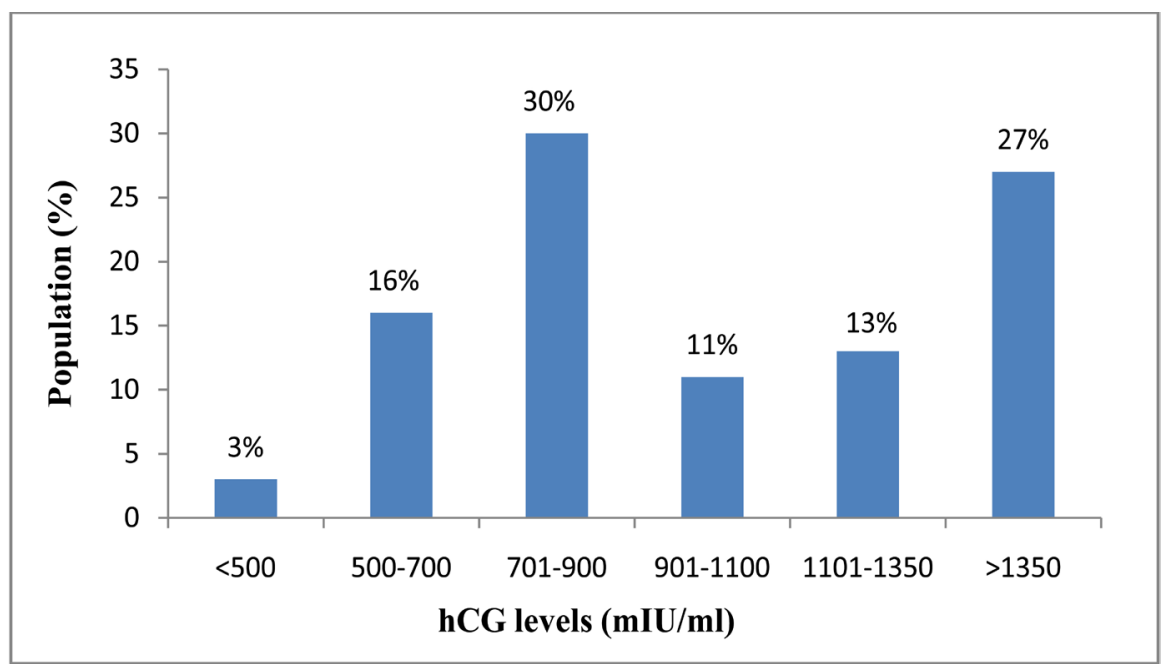

Figure 5. Distribution of respondents' hCG levels. 


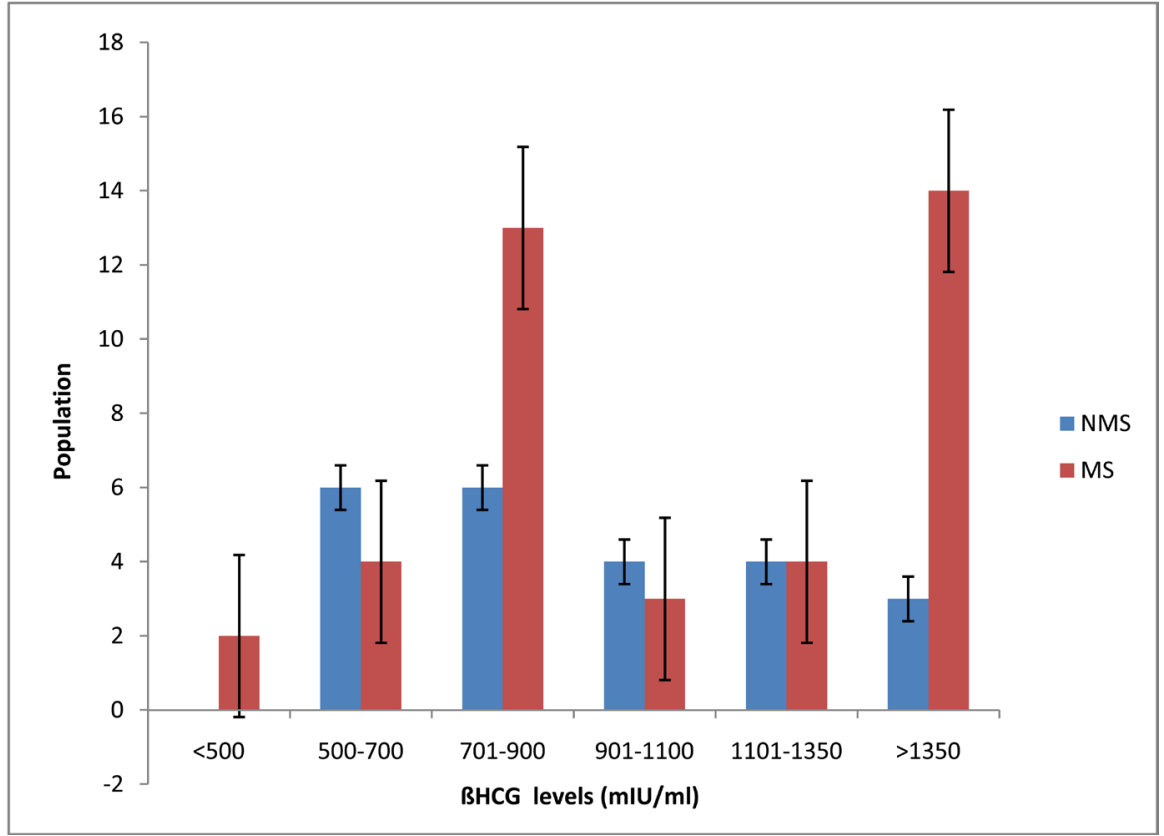

Figure 6. Respondents' hCG levels and morning sickness.

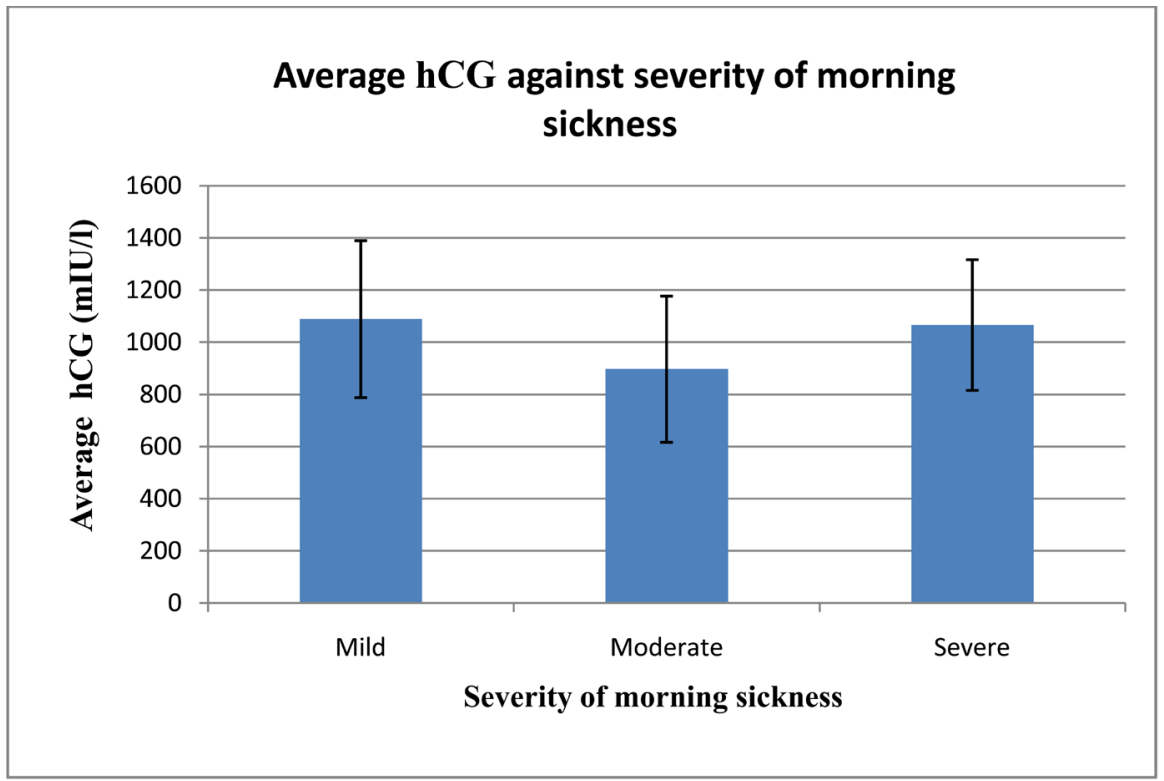

Figure 7. Average hCG and severity of morning sickness.

having higher hCG levels.

\subsection{Correlation between Urinary hCG Levels and Severity of Morning Sickness among Women Who Attend ANC at IAH}

\subsection{1. hCG and Severity of Morning Sickness}

Analysis of results depicted in Figure 7 above, using One way Analysis of Variance (ANOVA), it was found that there was no significant relationship between hCG levels and severity of morning sickness because the calculated $p$ value is greater than 0.05 . 


\subsubsection{Age and hCG Levels}

According to Figure 8, the mean values of hCG levels are different for given ranges of age in years. However, since the positive error bars of standard deviation are crossing each other, it signifies that there no statistical significance between the above two variables (Age and hCG levels). When comparisons were made using Turkey's Pairwise test, there is no significant relationship between hCG levels and age in years since the $\mathrm{p}$ values are the same, across different age groups. Furthermore, the $\mathrm{p}$ values were found to be greater than 0.05 (that is 20 years and below, $\mathrm{P}$ values are 0.8853 and $0.5082 ., 21$ - 30 years, $\mathrm{P}$ values are 0.6659 and $0.796 ., 31$ - 40 years, $P$ values are 1.578 and 0.9121 ) an indication that there is no significant relationship between hCG levels and age.

\subsubsection{Age and Incidence of Morning Sickness}

From Figure 9, there is no significant correlation between age and severity of

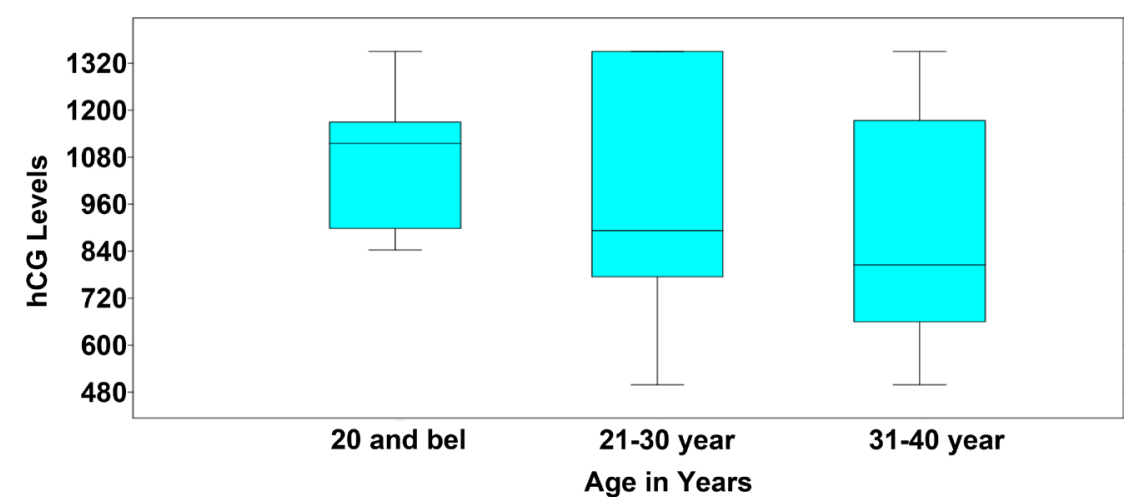

Figure 8. Correlation between age and hCG levels.

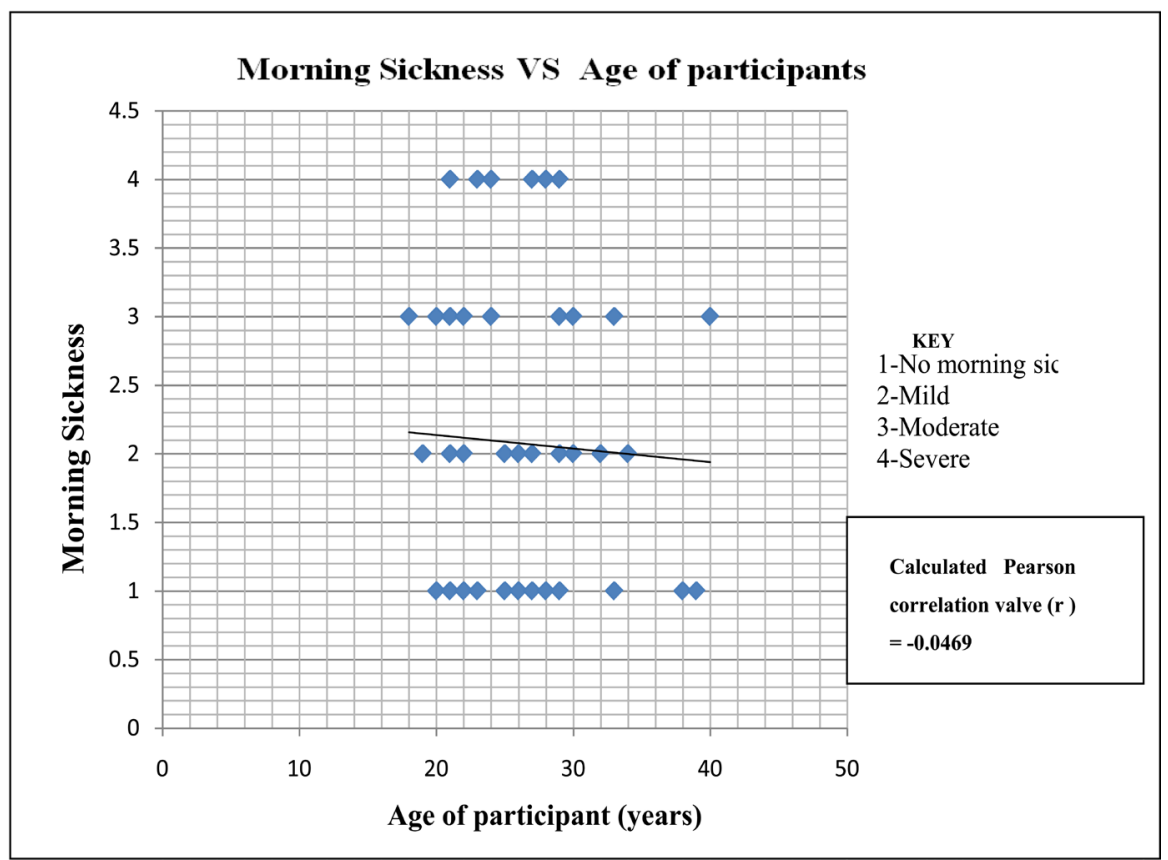

Figure 9. A scatter plot showing relationship between age and incidence of morning sickness. 
morning sickness since the participants' age is neither increasing nor decreasing with severity of morning sickness.

\subsection{4. hCG Levels and Weight of Respondents}

As presented in Figure 10, it shows that there no significant relationship between hCG levels and Weight since Pearson correlation (r) is equal to 0.157. If there was a positive relationship, the $r$ value would have ranged from 0.5 to 1 . Concerning the above figure, all the plotted values for weight were concentrated in one area; this means that the average weight of all the respondents was almost the same for almost the same hCG levels.

\subsubsection{Family History versus hCG Level}

As indicated in Figure 11, although the mean hCG levels for different family histories are different, the error bars are almost crossing each other when a pre-

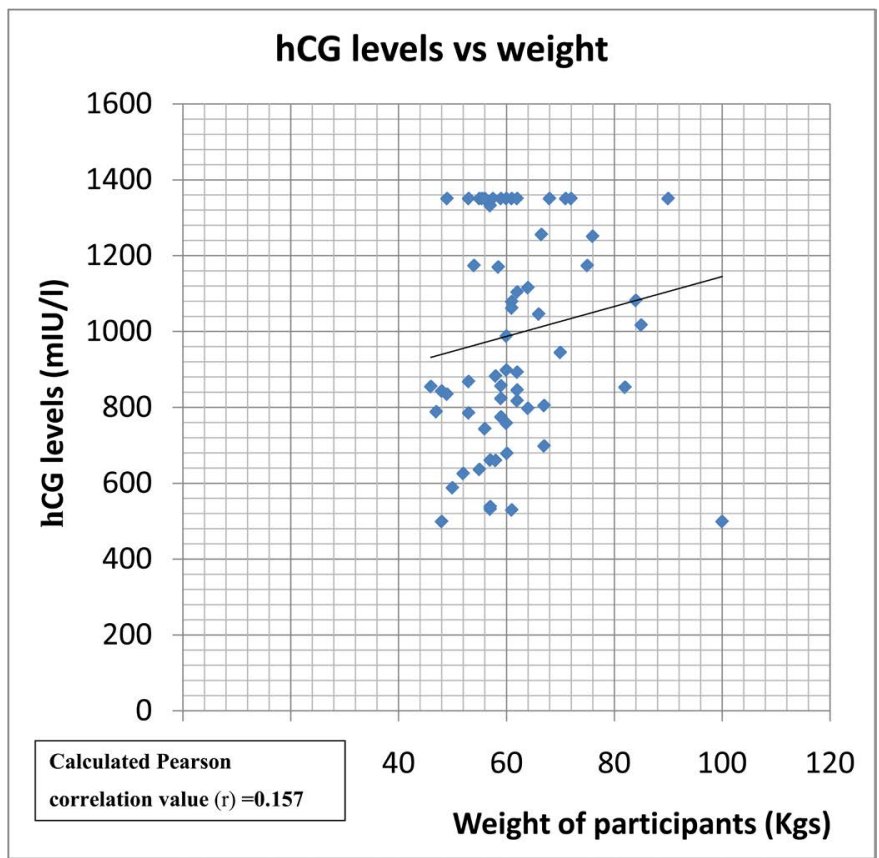

Figure 10. A scatter plot showing correlation between hCG and weight.

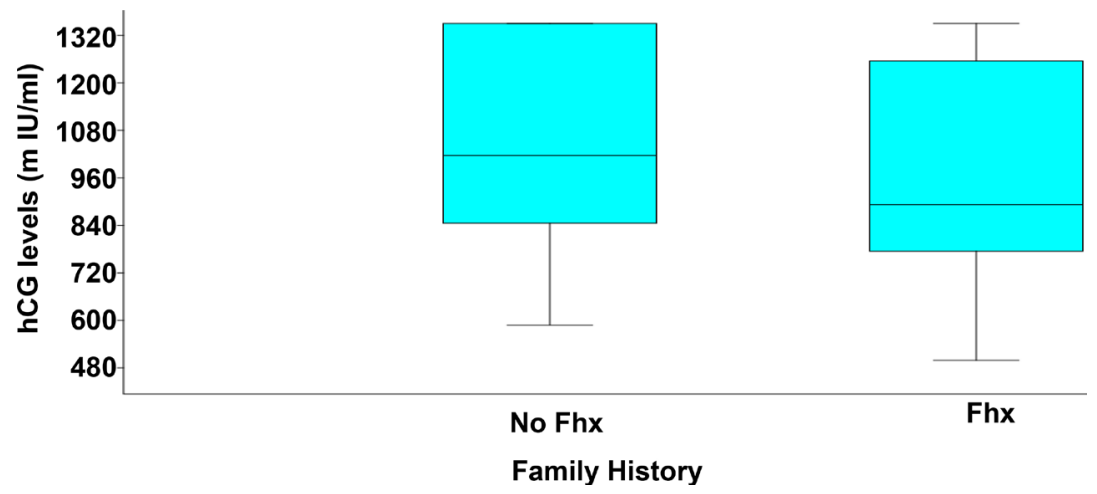

Figure 11. Correlation between family history and hCG levels. 
liminary line is drawn across the bars. Therefore there is no significant relationship between family history and hCG levels.

\subsubsection{Gravidity and hCG Levels}

As presented in Figure 12, there is no significant relationship between hCG levels and gravidity. This is because gravidity is neither increasing nor decreasing with either increase or decrease in hCG levels. The calculated Pearson correlation $(r)$ value is -0.05186 , signifying no correlation.

\subsubsection{Gravidity, Morning Sickness/hCG Levels}

From Figure 13, there is no significant relationship between the three variables since hCG levels are neither increasing nor reducing with gravidity and morning sickness.

\subsubsection{Cravings versus Morning Sickness}

From Figure 14, there is no significant correlation between respondents with no morning sickness and those with morning sickness as far as cravings are con-

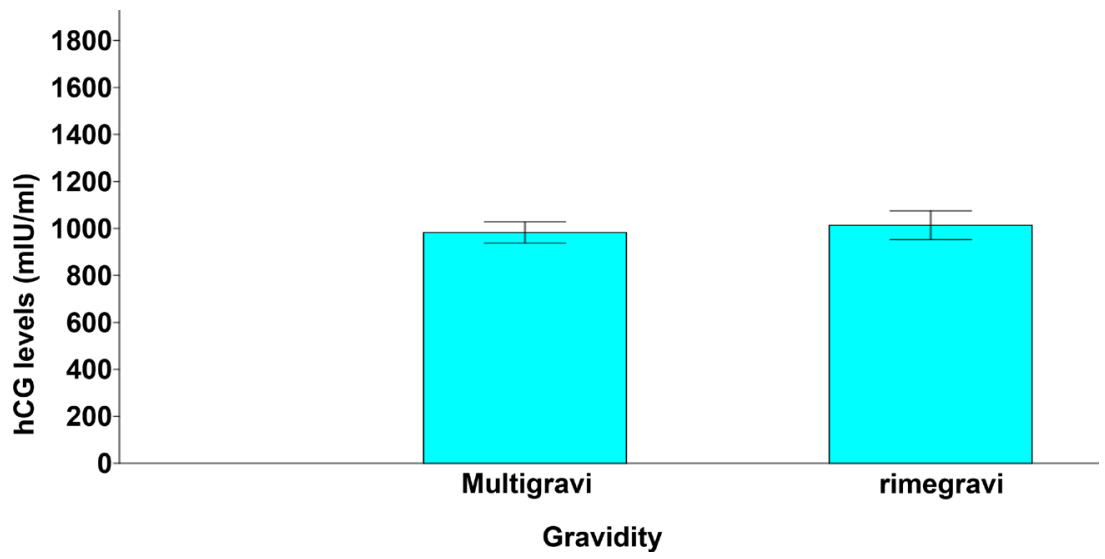

Figure 12. Relationship between gravidity and hCG levels.

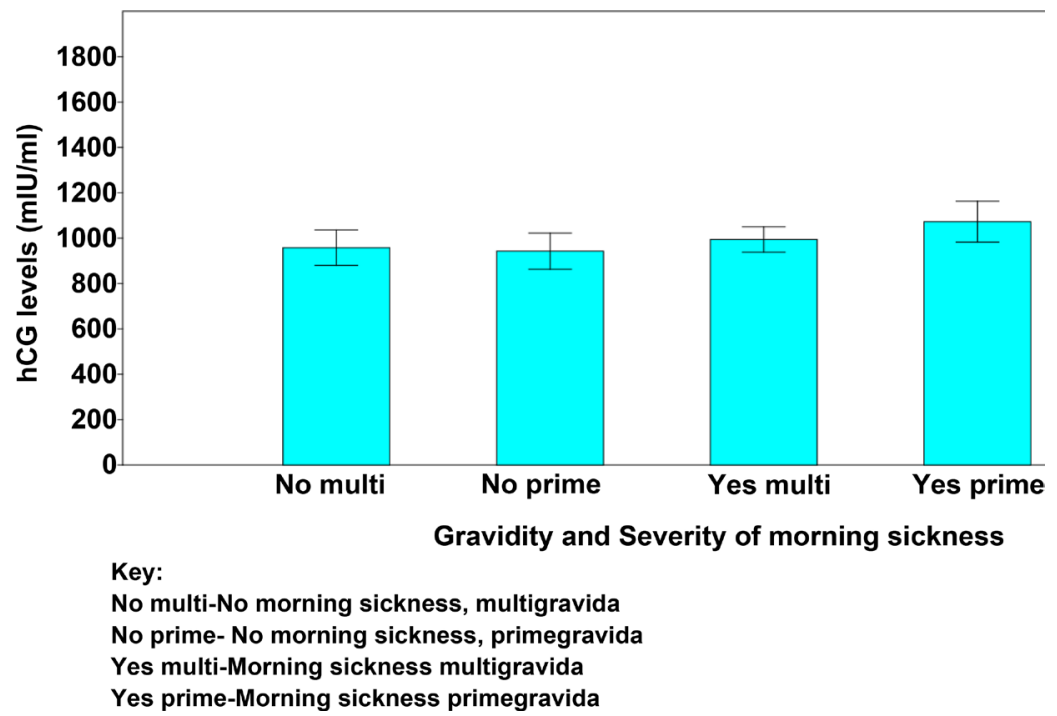

Figure 13. Relationship between gravidity, morning sickness/hCG levels. 


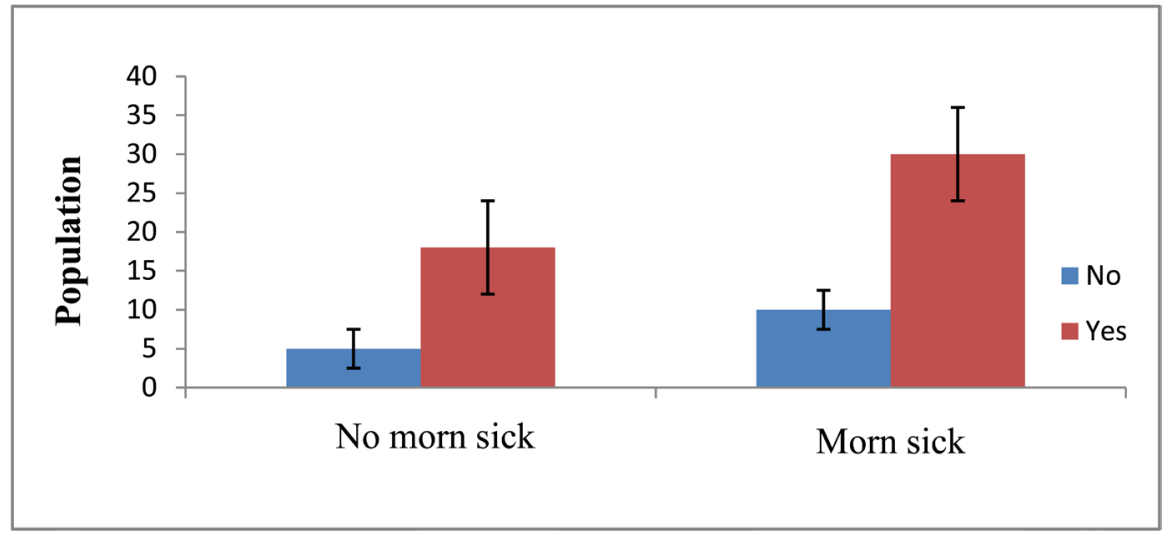

Figure 14. Relationship between cravings and morning sickness.

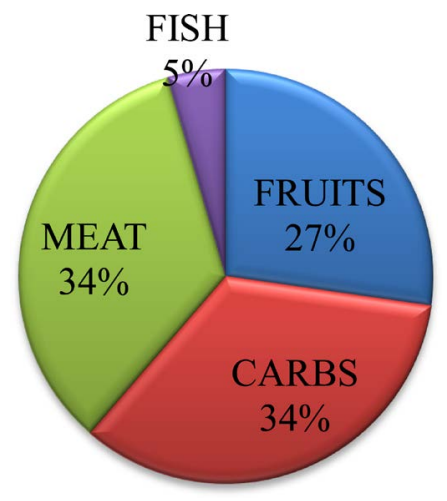

Figure 15. Respondents' most craved foods.

cerned. This is because there is a high population with cravings irrespective of morning sickness status. Hence the calculated Pearson correlation value is $-0.0262$

\subsubsection{Respondents' Most craved Foods}

As indicated in the Figure 15,34\% of the total respondents craved carbohydrates and the same percentage craved meat. This is because respondents acquire energy from carbohydrates for their developing fetuses. These respondents consumed meat to derive iron as well as proteins to maintain hemoglobin content as well as building the body for their fetuses respectively. Also $27 \%$ of the total respondents craved for fruits to acquire vitamins to protect the pregnant women from morning sickness while only $5 \%$ of the total respondents craved for fish to supply the growing fetuses and the pregnant women with fatty acids like omega-3.

\subsubsection{Aversions and Severity Morning Sickness}

From Figure 16, there is no correlation between respondents with aversions and severity of morning sickness, since the population with aversions does not increase with increase in severity of morning sickness. Furthermore, even those with no morning sickness were facing aversions meaning that aversions are common in pregnant women. Hence the calculated Pearson correlation is 0.227. 


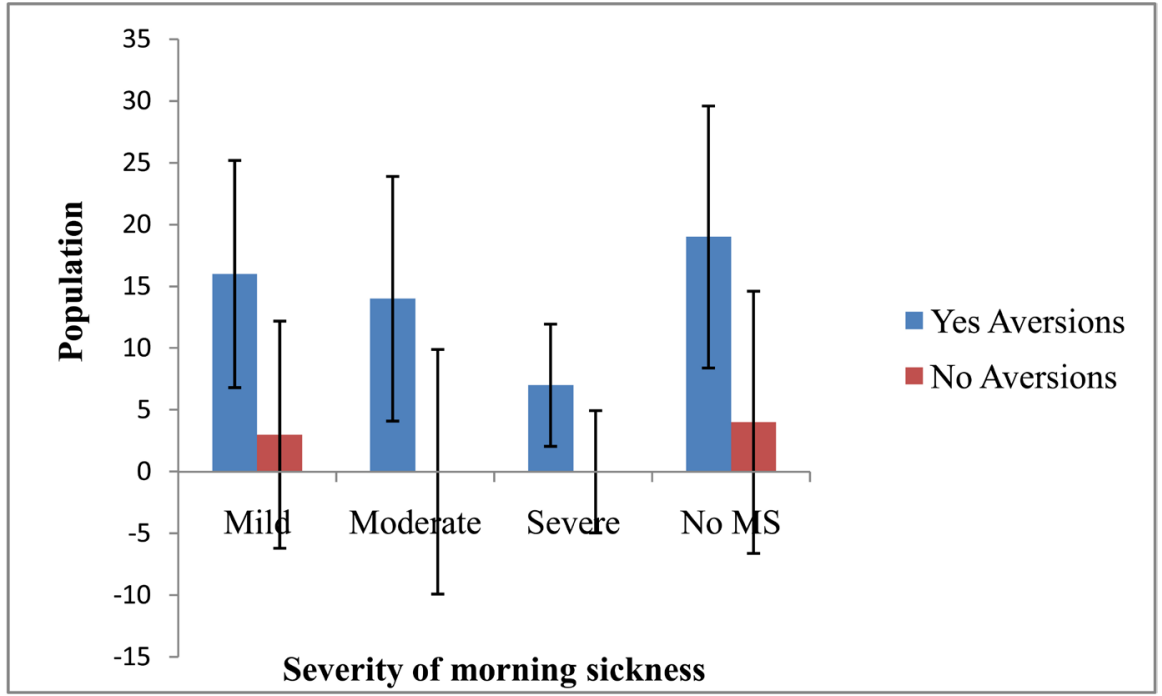

Figure 16. Correlation between aversions and severity morning sickness.

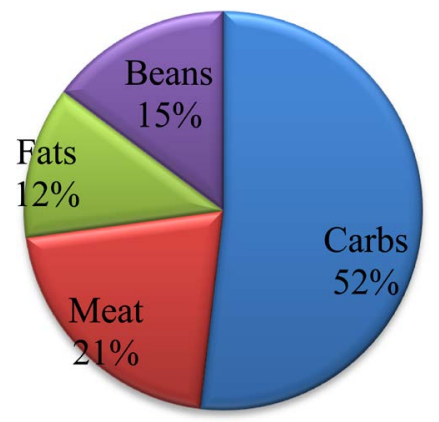

Figure 17. Respondents' most aversive foods.

\subsubsection{Respondents' Most Aversive Foods}

As presented in the Figure 17, 52\% of the total respondents disliked carbohydrates simply because most pregnant women dislike almost all types of foods. Otherwise carbohydrates easily pass through placental arteries to supply the fetus with energy necessary for growth and development, $21 \%$ of the total respondents disliked meat while $15 \%$ disliked beans. This is because too much protein tends to be harm full to the fetus by forming free radicals unlike carbohydrates which have phytonutrients which are antioxidants and $12 \%$ of the total respondents disliked fats since they break down to form free radicals which overwhelm the body's ability to regulate them leading to oxidative stress.

\subsubsection{Respondents' Morning Sickness Relieving Factors}

From Figure 18, the biggest percentage (48\%) of the total respondents reported no factor that could relieve their morning sickness. The relieving factors in the descending order of their importance as far as the percentage of their importance included ginger (12\%), wild millet (10\%), foods and herbs (9\%) although it is not recommended to consume herbs before term to avoid teratogenic effects while $7 \%$ and $5 \%$ of the total respondents revealed that fruits and multi-vitamins respectively relieved their morning sickness since both are reach in phytochemi- 


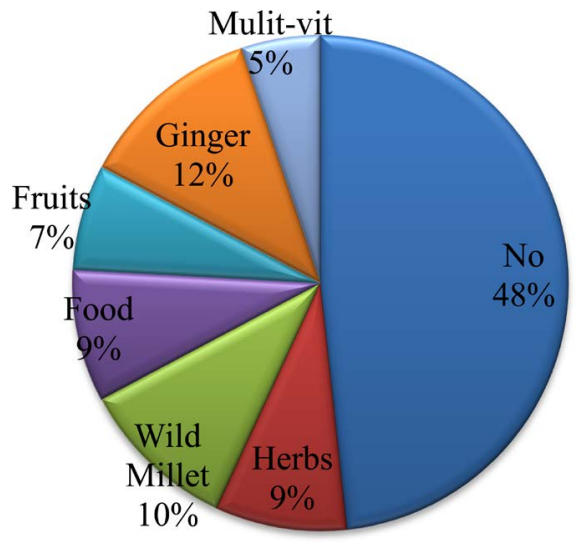

Figure 18. Respondents' morning sickness relieving factors.

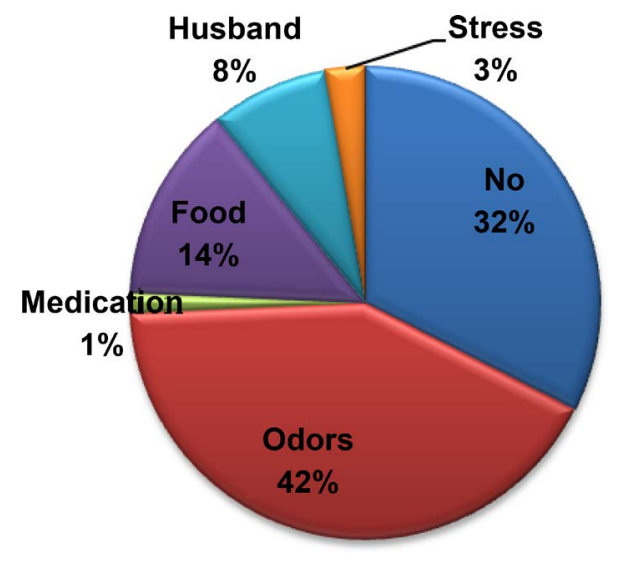

Figure 19. Respondents' morning sickness aggravating factors.

cals which counteract the effects of toxins in foods.

\subsubsection{Respondents' Morning Sickness Aggravating Factors}

From Figure 19, the biggest percentage (42\%) of the total respondents' morning sickness was aggravated by odors. This is because the sense of smell is linked to memories and emotions. Furthermore odor information is stored in a long term memory which has strong connections to emotional memory. This is due to the olfactory system's close association to limbic system (involved in emotion) and hippocampus (involved in place memory). However 32\% of the total respondents had no aggravating factor for morning sickness. Other aggravating factors included food (14\%), husband (8\%), stress (3\%) and only $1 \%$ of the total respondents' morning sickness was aggravated by taking oral treatments.

\section{Discussions}

\subsection{Prevalence of Morning Sickness}

From the findings of the study, majority (63\%) of the respondents experienced morning sickness. This is in line with Gadsby et al. [19], who reported that the prevalence of nausea, retching and vomiting in early pregnancy ranges from $50 \%$ - $85 \%$ in Western population. Furthermore, the study findings indicate that only 
$11 \%$ of the respondents had the severe form of morning sickness, with the majority (30\%) experiencing a mild form and $22 \%$ experienced moderate form of morning sickness. The percentage with severe morning sickness is in agreement with the findings by Kallen and Metteti [20], who reported that the percentage of pregnant women who experienced severity of nausea ranged from $10 \%-20 \%$.

\subsection{Relationship between Risk Factors and Morning Sickness}

\subsubsection{Weight and Severity of Morning Sickness}

The findings of the study indicate that there no significant relationship between average weight and severity of morning sickness among respondents. This is in line with Lacroix et al. [21], who reported that there is no relationship between body weight and morning sickness. This is because hCG increases weight loss due to its effect on caloric restriction [22].

\subsubsection{Cravings and Morning Sickness}

As per the findings of the study, $34 \%$ of the respondents craved for carbohydrates, the same percentage craved for meat, $27 \%$ for fruits and $5 \%$ craved for fish. This could be because carbohydrates serve as an energy source for both the mother and developing fetus, with the need for iron and proteins being justified by the need to maintain hemoglobin content as well as building the body for the fetus. Fruits serve as sources of vitamins that are of great importance to the pregnant mothers and foetus with fish supplying the growing fetus and the pregnant woman with essential fatty acids like omega-3 [23] although Hibbein et al. [24] and Oken et al. [25] discourage consumption of the big types of fish like sharks repeatedly since they lead to poor development of the fetus' nervous system [24] [25]. The findings of the study indicate that there is no correlation between morning sickness and cravings. They contend that some cravings signal nutritional deficiencies so that the response becomes a mechanism to meet the bodies' need for extra calories. More so, cravings may be due to changing sensitivities, smell and tastes during pregnancy [26]. These findings agree with Crystal et al. [4] who reported that women with severe nausea showed no association with cravings.

\subsubsection{Aversions and Severity of Morning Sickness}

When aversions were considered, it was found that there was no correlation between aversions and severity of morning sickness. This could be a result of an adaptation by the woman's body to avoid some foods that could be harmful to the developing foetus. This tends to be in agreement with the finding of Zhang and Wen-Wei [6], that aversions are mechanism for preventing the embryos' exposure to pathogens and harmful chemicals [6].

\subsubsection{Respondents' Morning Sickness Aggravating Factors}

From the findings of the study, majority of the total respondents' revealed that morning sickness was aggravated by odors for example cooking odors, food odors and non-food odors like perfumes and cleaning products. This is because 
the sense of smell is linked to memories and emotions. Furthermore odor information is stored in a long term memory which has strong connections to emotional memory [27]. This is because olfactory system is closely associated with limbic system (involved in emotion) and hippocampus (involved in place memory) [28]. In addition, other respondents revealed that morning sickness was aggravated by food consumption especially after consuming the same food for long. This means that craved foods can be aversive if consumed repeatedly. Other than the already named physiological factors, some respondents were affected by psychological stress (husbands) and physiological stress (fatigue).

\subsection{Urinary hCG Levels among Women}

\subsubsection{Respondents' hCG Levels Distribution}

From the results, a bimodal distribution of beta hCG levels among first trimester pregnant women was shown. Two medians were centered at approximately $500-$ $700 \mathrm{mIU} / \mathrm{l}$ for lower hCG distribution and 1101 - $1350 \mathrm{mIU} / \mathrm{l}$ for higher hCG distribution. Therefore two different groups were shown on the histogram. There was a high population (30\%) having lower hCG levels (701 - $900 \mathrm{mIU} / \mathrm{l})$ and another high population (27\%) having high hCG levels (>1350 mIU/l).

\subsubsection{Age and hCG Levels}

As per the study findings, the mean values of hCG levels were different for given ranges of age in years. However, there was no positive correlation between the above two variables (age and hCG levels). In support of this, Smith et al. [9] reported that women's age is not related to symptoms of morning sickness especially to hyperemesis gravidarum. However, the findings do not agree with Kallen et al. [20] who reported that morning sickness is more common in younger pregnant women than older ones.

\subsubsection{Family History versus hCG Levels}

From the findings of the study, although the mean hCG levels for different family histories are different, hCG levels are neither increasing nor decreasing with either absence or presence of family history of morning sickness. Therefore there is no significant relationship between family history and hCG levels. However, this disagrees with Gadsby et al. [19] who reported that women whose mothers had trouble with morning sickness symptoms were more likely to have similar symptoms. This could be a result of the fact that some pregnant women were taking multivitamins both before conception and during gestation which might have prevented the occurrence morning sickness.

\subsubsection{Gravidity and hCG Levels}

From the findings of the study, there is no significant relationship between Gravidity and hCG levels. This could be attributed to the fact that after the ninth week of pregnancy, the placenta starts producing high levels of estrogen and progesterone while hCG levels are falling at the same time. Therefore, hCG is no longer needed to stimulate the ovaries to make ovarian hormones. Hence no 
correlation between hCG levels and morning sickness.

\subsection{Correlation between Urinary hCG Levels and Severity of Morning Sickness}

The study findings indicate that there is no significant relationship between hCG levels and severity of morning sickness. Findings do not agree with Goodwin et al. [14] who reported correlation between hCG and morning sickness. Furthermore, a bimodal hCG distribution was shown among first trimester pregnant women. A high population with morning sickness had low hCG levels (701 - 900 $\mathrm{mIU} / \mathrm{l})$ and also a high population with morning sickness had high hCG levels (>1350 mIU/l). Also, a high population with no morning sickness had low hCG levels (701 - $900 \mathrm{mIU} / \mathrm{l})$ and a high population with no morning sickness had high hCG levels (901 - $1100 \mathrm{mIU} / \mathrm{l}, 1101-1350 \mathrm{mIU} / \mathrm{l})$. This shows that there is no significant relationship between hCG and morning sickness. Form these results; it indicates that there are other factors that caused morning sickness other than hCG levels. For example estrogen as reported by Goodwin et al. [14].

\section{Conclusion}

From the study findings, it can be concluded that the prevalence of morning sickness in the study population was high (at 63\%) although the most prevalent form was the mild one with no case of hyperemesis gravidarum recorded. With regard to relationship between risk factors and severity of morning sickness, there was no positive correlation between physiological characteristics (gravidity, age and weight) of respondents and morning sickness. There was also no correlation between cravings as well as aversions and morning sickness. In addition, the study findings showed no positive correlation between hCG levels and severity of morning sickness in the study population, which contradicted some of the findings in some previous studies.

\section{References}

[1] Flaxman, S.M. and Sherman, P.W. (2000) Morning Sickness, a Mechanism for Protecting Mother and Embryo. The Quarterly Review of Biology, 75, 113-148. https://doi.org/10.1086/393377

[2] O’Brien, B. and Zhou, Q. (1995) Variables Related to Nausea and Vomiting during Pregnancy. Birth, 22, 93-100. https://doi.org/10.1111/j.1523-536X.1995.tb00566.X

[3] Boneva, R.S., Moore, C.A., Botto, L., Wong, Y. and Erickson, J.D. (1999) Nausea during Pregnancy and Congenital Heart Defects: A Population Based Case Control Study. American Journal of Epidemiology, 149, 717-725.

https://doi.org/10.1093/oxfordjournals.aje.a009880

[4] Crystal, S.R., Bowen, D.J. and Bernstein, I.L. (1999) Morning Sickness and Salt Intake, Food Craving and Food Aversions. Physiology and Behaviour, 67, 181-187. https://doi.org/10.1016/S0031-9384(99)00055-4

[5] Dodds, L., Fell, D.B., Joseph, K.S., Allen, V.M. and Butler, B. (2006) Outcomes of Pregnancies Complicated by Hyperemesis Gravidarum. Obstetrics and Gynaecology, 107, 285-292. https://doi.org/10.1097/01.AOG.0000195060.22832.cd 
[6] Zhang, J. and Cai, W.W. (1991) Severe Vomiting during Pregnancy: Antenatal Correlation and Fetal Outcomes. Epidemiology, 2, 454-457. https://doi.org/10.1097/00001648-199111000-00013

[7] Tsang, S., Katz, V.L. and Wells, S.D. (1996) Maternal and Fetal Outcomes in Hyperemesis Gravidarum. International Journal of Gynaecology and Obstetrics, 55, 231-235. https://doi.org/10.1016/S0020-7292(96)02778-6

[8] Gadsby, R., Barnie-Adshead, A.M. and Jagger, C. (1997) Pregnancy Nausea Related to Women's Obstetric and Personal Histories. Gynaecologic and Obstetric Investigation, 43, 108-111. https://doi.org/10.1159/000291833

[9] Smith, C., Crowther, C., Beilly, J. and Dandeaux, J. (2000) The Impact of Nausea and Vomiting on Women: A Burden of Early Pregnancy. Australian and New Zealand Journal of Obstetric Gynaecology, 40, 397-400.

https://doi.org/10.1111/j.1479-828X.2000.tb01167.x

[10] Baird, D.D., Weinberg, C.R., McConnaughey, D.R. and Wilcox, A.J. (2003) Rescue of the Corpus Luteum in Human Pregnancy. Biology of Reproduction, 68, 448-456. https://doi.org/10.1095/biolreprod.102.008425

[11] Grün, J.P., Meuris, S., De Nayer, P. and Glinoer, D. (1997) The Thyrotrophic Role of Human Chorionic Gonadotrophin (hCG) in the Early Stages of Twin (Versus Single) Pregnancies. Clinical Endocrinology, 46, 719-725. https://doi.org/10.1046/j.1365-2265.1997.2011011.x

[12] Perrier d'Hauterive, S., Berndt, S., Tsampalas, M., Charlet-Renard, C., Dubois, M., Bourgain, C., Hazout, A., Foidart, J.M. and Geenen, V. (2007) Dialogue between Blastocyst hCG and Endometrial LH/hCG Receptor: Which Role in Implantation? Gynecologic Obstetric Investigation, 64, 156-160. https://doi.org/10.1159/000101740

[13] Goodwin, T.M., Hershman, J.M. and Cole, L. (1994) Increased Concentration of Free $\beta$ Subunit of Human Chorionic Gonadotropin in Hyperemesis Gravidarum. Acta Obstetricia et Gynecologica Scandinavica, 73, 770-772. https://doi.org/10.3109/00016349409072502

[14] Goodwin, T.M., Poursharif, B., Korst, L.M., MacGibbon, K. and Fejzo, M.S. (2002) Hormone Profile of Kuwaiti Women with Hyperemesis Gravidarum. Obstetrics and Gynecology, 266, 218-222.

[15] Jordan, V., Grebe, S.K.G., Cooke, R.R., Ford, H.C., Larsen, P.D., Stone, P.R. and Salmond, C.E. (1999) Acidic Isoforms of Chorionic Gonaditrophin in European and Samoan Women Are Associated with Hyperemesis Gravidarum and May Be Thyrotrophic. Clinical Endocrinology, 50, 619-627. https://doi.org/10.1046/j.1365-2265.1999.00702.x

[16] Al-Yatama, M., Diejomaoh, M., Nanda Kumaran, M., Monem, R.A., Omu. A.E. and Al Kandari, F. (2002) Hormone Profile of Kuwaiti Women with Hyperemesis Gravidarum. Archives Gynecology and Obstetrics, 266, 218-222. https://doi.org/10.1007/s004040100210

[17] O’Connor, K.A., Holman, D.J., Miller, R.C., Barsom, S.H. and Wood, J.W. (2004) Pregnancy Related Sickness in Rural Bangladesh: Symptoms and Their Links with Reproductive Hormones. Human Reproduction, CSDE Working Paper No. 04-07, CSDE, University of Washington, Washington DC.

[18] Krejcie, R.V. and Morgan, D.W. (1970) Determining Sample Size for Research Activities. Educational and Psychological Measurement, 30, 607-610. https://doi.org/10.1177/001316447003000308

[19] Gadsby, R., Barnie-Adhead, A.M. and Jagger, C. (1993) A Prospective Study of 
Nausea and Vomiting during Pregnancy. British Journal of General Practice, 43, 245-248.

[20] Kallen, B., Lunderg, G. and Aberg, A. (2003) Relationship between Vitamin Use, Smoking and Nausea and Vomiting of Pregnancy. Acta Obstetricia et Gynecologica Scandinavica, 82, 916-920. https://doi.org/10.1034/j.1600-0412.2003.00307.x

[21] Lacroix, R., Eason, E. and Mel Zack, R. (2000) Nausea and Vomiting during Pregnancy: A Prospective Study of Its Frequency, Intensity and Patterns of Change. American Journal of obstetrics Gynecology, 182, 931-937. https://doi.org/10.1016/S0002-9378(00)70349-8

[22] Simeons, A.T.W (2010) Pounds and Inches: A New Approach to Obesity. https://www.dropbox.com/s/qg453fxjscmfigm/pounds-and-inches-by-dr-a-t-w-sim eons.pdf

[23] Kris-Etherton, P.M., Harris, W.S. and Appel, L.J. (2002) Fish Consumption, Oil Fish, Omega-3-Fatty Acids and Cardiovascular Disease. Circulation, 106, 2747 2757. https://doi.org/10.1161/01.CIR.0000038493.65177.94

[24] Hibbein, J.R., Davis, J.M. and Steer, C. (2007) Maternal Seafood Consumption in Pregnancy and Neuro-Developmental Outcomes in Childhood (ALSPAC Study): An Observational Cohort Study. Lancet, 309, 578-585. https://doi.org/10.1016/S0140-6736(07)60277-3

[25] Oken, E., Wright, R.O. and Weinman, K.P. (2005) Maternal Fish Consumption, Hair Mercury and Infant Cognition in a U.S Cohort. Environmental Health Perspective, 113, 1376-1380. https://doi.org/10.1289/ehp.8041

[26] Demissie, T., Muroki, N. and Goi-Makau, W. (1998) Food Aversions and Cravings during Pregnancy: Prevalence and Significance for Maternal Nutrition in Ethiopia. Food and Nutrition Bulletin, 19, 20-26. https://doi.org/10.1177/156482659801900104

[27] Cahill, L. and McGaugh, J.L. (1996) Modulation of Memory Storage. Current Opinion in Neurobiology, 6, 237-242. https://doi.org/10.1016/S0959-4388(96)80078-X

[28] Addis, D.R., Moscovitch, M., Crawley, A.P. and McAndrews, M.P. (2004) Re-Collective Qualities Modulate Hippocampal Activation during Autobiographical Memory Retreval. Hippocampus, 14, 752-762.https://doi.org/10.1002/hipo.10215 
Submit or recommend next manuscript to SCIRP and we will provide best service for you:

Accepting pre-submission inquiries through Email, Facebook, LinkedIn, Twitter, etc. A wide selection of journals (inclusive of 9 subjects, more than 200 journals)

Providing 24-hour high-quality service

User-friendly online submission system

Fair and swift peer-review system

Efficient typesetting and proofreading procedure

Display of the result of downloads and visits, as well as the number of cited articles Maximum dissemination of your research work

Submit your manuscript at: http://papersubmission.scirp.org/

Or contact jbm@scirp.org 